Article

\title{
Profiling Spanish Prospective Buyers of Electric Vehicles Based on Demographics
}

\author{
Jose Esteves ${ }^{1}$, Daniel Alonso-Martínez ${ }^{2}$ and Guillermo de Haro ${ }^{3, *}$ \\ 1 Department of Information Systems and Technology, IE Business School, 28006 Madrid, Spain; \\ jose.esteves@ie.edu \\ 2 Facultad de Ciencias Económicas y Empresariales, Campus de Vegazana s/n, Universidad de León, \\ 24071 León, Spain; dalom@unileon.es \\ 3 Departamento de Dirección Estratégica, Emprendimiento e Innovación, EAE Business School, \\ 28002 Madrid, Spain \\ * Correspondence: guillermo.de.haro@campus.eae.es; Tel.: +34-900-494-805
}

\section{check for}

updates

Citation: Esteves, J.;

Alonso-Martínez, D.; de Haro, G.

Profiling Spanish Prospective Buyers

of Electric Vehicles Based on

Demographics. Sustainability 2021, 13 ,

9223. https://doi.org/10.3390/

su13169223

Academic Editors: Miguel Cuerdo

Mir, Luis Miguel Doncel Pedrera,

Jorge Sainz-González and Marc

A. Rosen

Received: 25 May 2021

Accepted: 13 August 2021

Published: 17 August 2021

Publisher's Note: MDPI stays neutral with regard to jurisdictional claims in published maps and institutional affiliations.

Copyright: (C) 2021 by the authors. Licensee MDPI, Basel, Switzerland. This article is an open access article distributed under the terms and conditions of the Creative Commons Attribution (CC BY) license (https:/ / creativecommons.org/licenses/by/ $4.0 /)$.

\begin{abstract}
As traffic congestion and air pollution rise at alarming rates in many cities worldwide, new smart technologies are emerging to meet the urban mobility challenge. In addition, automotive firms have transformed their business models to make them more sustainable and to adjust to demand response. Electric vehicles (EVs) represent a viable option to reduce ecological damage and improve public health. However, in the previous literature, no consensus has been reached on the profile of prospective buyers of EVs. Based on a large-scale sample of Spanish citizens and using cluster analysis, our study provides a better understanding of the demographics of such prospective buyers. We identified four types of EV prospective buyers. Our results show that although men have a strong preference for EVs, low-income older women prove to be the most EV-aware group; their automotive driving experience and concern for sustainability could be among the underlying causes of this particular interest. Another valuable insight is the greater partiality of older people for EVs. These findings have many implications for managers, especially in the automotive industry, policymakers, and sustainability strategists. They show that EV prospective buyers should not be approached as a homogeneous group but as a heterogeneous group with different socio-demographic characteristics that might help decision-makers make better business decisions.
\end{abstract}

Keywords: electric vehicles; smart urban mobility; electromobility; demand response; automotive market; sustainability

\section{Introduction}

We are living in unprecedented times that require rethinking the way we live and shaping sustainable lifestyles. The ongoing Global COVID-19 pandemic could have a lasting impact on mobility as it drives change in the macroeconomic environment, workplace practices, regulatory trends, sustainability, technology, and consumer behaviours [1] Population mobility has a significant effect on the COVID-19 epidemic [2]. Previous studies have shown an association of ambient temperature with COVID-19 infection [3], which will highly likely contribute to modifying the types of vehicles sold and reinforce the sales of EVs.

New mobility patterns provide a strategic opportunity to transition to a greener and smarter mobility system and EV ecosystem growth [4]. Today, 55\% of the world's population lives in urban areas, a proportion that may increase to $68 \%$ by 2050 [5]. As urban inhabitants grow, existing and emerging cities face the challenge of becoming more sustainable and meeting rising demands for efficient urban mobility within limited physical infrastructure capacity. Simultaneously, citizens' expectations are changing continually, influenced by ongoing innovations around information technology, low-carbon and efficient vehicle technologies, and improvements in infrastructure management (see [6], for 
a review). EV usage has been a growing trend in the sharing economy mobility models [7]. One of the main sectors affected by this change is the automotive sector which in Spain represents $10 \%$ of the GDP and $19 \%$ of total Spanish exports. The industry generates 300,000 direct jobs and up to 2 million, including indirect employment. Spain is the second-largest automobile manufacturer in Europe and the eighth largest worldwide.

Within the smart-city ecosystem, particularly in smart and electromobility, the adoption of EVs in urban environments has increased considerably over the last decade. EVs are transforming transportation and urban mobility. Automotive firms have a great challenge ahead but also an excellent opportunity to satisfy demand response. The global EV market was valued at $\$ 162.34$ billion in 2019 and will reach $\$ 802.81$ billion by 2027 [8]. An example of how a company can increase its market value through EV is Tesla. This firm is considered a reference in the market with $100 \%$ of EV. Although its sales are not comparable with combustion motors firms, it has become the most valuable automotive manufacturer by market capitalisation.

As a result, EVs have grown exponentially in recent years, but we miss more insights about the characteristics of their prospective buyers. Previous literature suggested that many factors determine the perception of buyers toward EVs. Among others, sociodemographic characteristics, economic, environmental, and technological factors [9-11] are the most important. Socio-demographic characteristics have attracted a great deal of attention as key profiling variables $[12,13]$. Previous studies assert that demographic variables such as age, gender, income, level of education, household composition, and psychological factors exert a significant influence on EV adoption and determine the demand response of electromobility [13]. However, although these studies highlight the relevance of demographics, there is relative agreement on which factors have a more decisive influence on EV adoption [9-11] and in which context (see [11], for a review). Also, demand for technological products can show different motivations as the adoption grows [14], making the understanding of when consumers may "cross the chasm" very important [15].

Therefore, the research question guiding this research study is: What are the main socio-demographic factors that may affect EV adoption? The main objective of this study is to perform a hierarchical cluster analysis using demographic variables (gender, age, educational level, and income) of a sample of Spanish citizens to understand the main socio-demographic factors that may affect $\mathrm{EV}$ adoption. Some scholars have highlighted that the relationships between these variables remain unclear, and explicit attempts to develop an integrated perspective have not been made yet $[11,16,17]$. Cluster analysis techniques have been used in the automotive industry $[18,19]$ as a tool to understand consumer structure [20] or behaviour regarding EV usage [21,22].

From the socio-demographics perspective, gender is one of the most analysed variables with disparities of results [23-27]. Gendered experiences of mobility have attracted considerable qualitative research attention $[24,28]$. Despite the increasing number of studies on the subject, existing research confirms that we do not know enough about the specific needs of men and women. In addition, some forecasts and trends confirm that the gender gap is still present and impacts smart-mobility patterns. We propose that both the challenges and opportunities regarding EV preference by gender are challenging to understand without a socio-demographic approach. And we consider that women and men have different EV preferences due to socio-demographic differences.

Previous research has also suggested that age plays a determining role since younger generations appear to be more concerned about technological, social, and environmental issues [16]. They have received specific training in sustainability and grown up with a wider technological gap. Similarly, current research has shown that more-educated people pay more attention to social and environmental issues [10,29]. Moreover, people with a higher educational level are generally more innovative and more likely to experiment with new products and services. In this line, [30] suggested that it is necessary to promote urban and infrastructure development through education. The higher educational level 
of these people enables them to learn about smart mobility more quickly [31]. Previous research shows that income and social status tend to influence the product's adoption positively [32-35]. Moreover, [13] (p. 18) argues "high-income consumers are likely to be more environmentally conscious because consumers with higher income can bear more".

Our findings shed light on and provide evidence of gender disparities in the adoption of EV preferences among Spanish users. In this regard, women's increased sustainability awareness is undeniable [36,37], the EV gender gap is evolving, and the role is sometimes inverted, as we show in our study. However, as previously mentioned, it is necessary to consider all the socio-demographic characteristics simultaneously. Gender-gap differences related to age, income, and educational level determine whether an individual has a proactive attitude toward EVs [13]. It is widely accepted that most educated people have greater social and environmental awareness [38,39].

Nevertheless, highly educated people exhibit several concerns regarding EVs, especially women, regardless of their purchasing power. However, the level of income of men seems to be determinant to acquire an EV. It is surprising that although young people have better knowledge of new technologies such as EVs [38,39], older people exhibit higher awareness of the EV option [40,41]. In addition to fewer drivers' licenses and the use of shared mobility services among young people, the cost of EVs could be behind their lower preference levels. Also, younger generations tend to drive less and share more [42] and consequently purchase fewer cars [43-45]. In this sense, understanding the socio-demographic profile of EV users and their purchase intention would help the EV market and urban mobility leaders to design the most appropriate EV strategies for different segments of citizens who vary in their preferences for EVs.

The remainder of this paper is structured as follows. First, we review the new mobility trend and main socio-demographic factors before presenting the research methodology. Then we continue with a discussion of our findings and their implications for research and practice. Finally, we conclude by reviewing our contributions, research limitations, and future research avenues.

\section{New Mobility Trend}

The world's urban population will increase from 4.2 billion in 2018 to 9.7 billion in 2050; an urban dweller will spend around $106 \mathrm{~h}$ per year in traffic jams, three times more time than today [5]. Urban transportation is almost entirely dependent (97\%) on petroleum-based fuels (gasoline and diesel) and only slightly on biofuels (1\%) and electrical energy (2\%) [46]. Another significant drawback of vehicular transportation is that around 1.35 million people die each year due to road traffic accidents [47]. Urban mobility in most cities is slowly changing. Cities are increasingly witnessing the impact of more disruptive change, whether because of technological innovation, eco-innovations, socio-economic transformation, or new policy interventions. Therefore, leaders must design new strategies to enhance urban development and electromobility. Sustainable mobility in urban areas is essential for the local and national economies [30]. EVs may help in the development and improvement of social sustainability strategies of urban mobility [48]. They facilitate reduced ecological damage to urban areas, solve environmental issues, and reduce citizens' stress on the road and in cities because such vehicles create less noise pollution.

For ecological and economic reasons, the usage of EVs in urban environments is becoming more attractive [16]. EVs do not cause any direct $\mathrm{CO}_{2}$ emissions during operation [49] and reduce increasing, substantial, long-term fuel costs as well as radiated noise [50]. However, the adoption of EVs poses several issues in terms of EV infrastructure management, especially concerning the related EV charging network. Such matters include providing charging stations, increasing peak load, and addressing voltage instability, harmonics, and thermal overload [51]. Some governments have developed policy measures to help introduce electromobility vehicles [52,53].

Although previous studies have analysed the relevance of demographic characteristics of prospective buyers of EVs $[10,11,33]$, the findings of this literature are far from 
unanimous. Previous studies assert that demographic factors have a positive impact on both pro-environmental behaviour (e.g., [12,54] and in product innovation adoption [55]. Gatignon and Robertson [55] demonstrated that demographic characteristics significantly influence new product adoption behavior, further suggesting that younger and more educated consumers with higher incomes tend to accept market innovations more quickly.

More specifically, European studies show that although men appeared to have a higher expressed propensity to purchase an EV (35.6\% in 2014, 41.3\% in 2018) compared to women $(28.2 \%$ and $33.6 \%$, respectively), these differences are not statistically significant [23]. They only found that income, level of education, and the number of charging stations per capita are substantial factors in the adoption; by contrast, age, gender, and employment are insignificant [23]. Similarly, [27] showed that gender, age, and educational level characteristics are relevant in adopting EVs in Sweden. Specifically, their main results showed that current EV drivers are men, well-educated, and have a medium-high income. Also, that EVs are used mainly for private purposes and charged at home during the night.

In summary, without overcoming or dealing with these socio-demographic factors, the EV market will not benefit from the advantages mentioned above that new EV adoption may offer [11]. Hardman et al. [56] studied early adopters of plug-in EVs, concluding that being an adopter does not necessarily lead to an interest in purchasing. To better understand the phenomenon, they used cluster analysis. Moreover, a cluster analysis is needed to uncover the similarity of citizens in terms of EV preferences [33]. Socio-demographic characteristics should be considered together. Accordingly, this paper addresses the most relevant socio-demographic factors according to previous literature: gender, age, educational level, and income.

\subsection{Gender Mobility}

Adopting a gender perspective in transportation policies is crucial to reduce gender inequalities and support more environmentally friendly development that considers women's environmental behaviour $[25,26]$. There are well-documented gender differences that show that women's mobility patterns differ from men's $[9,23,27]$. For a long time, these differences have not been considered in transportation planning. Urban transportation planning and policy-making worldwide have remained strictly influenced by standard procedures and methodologies developed in the course of the last 40 years and based mainly on men's mobility patterns: individual journeys to work during rush hours by private motorised transportation.

Attention to gender and transportation has grown at the level of the "grey" literature, i.e., studies that remain outside the domain of academic publications commissioned by governmental and international agencies (WB, OECD, EC, UN, NGOs, etc.). Such studies provide information for planning processes that consider the gender perspective. These studies are particularly relevant for the adoption of new vehicles by women. Women value different characteristics than men: they are looking for practical, sturdy, and lesspolluting vehicles.

Although women's travel patterns have changed dramatically during the past few decades, different studies (e.g., [57]) have found persistent gender differences in travel mobility. Specifically, women are less likely to travel further, travel to higher destinations, travel more frequently with children, or go shopping [58]. These travel patterns affect the type of vehicle they might prefer because EVs are particularly well-considered for short distances. For example, in Spain, women were far more likely to utilise public transportation [59].

A study looking at four European countries (Germany, Norway, Greece, and Sweden) found that men consume more energy on transport than women [60]. Women use emissionsintensive modes of transportation at a lower rate than do men, their level of car ownership is lower, and their share of public transportation use is higher. All these factors must be considered in transportation and mobility planning and significantly influence EV users' preferences. Lately, European countries and cities have incorporated the principle of 
"gender mainstreaming" into urban mobility and transportation. Gender mainstreaming was first adopted as a general basis for social policy by the European Union in the Treaty of Amsterdam [61]. The transportation arena comprises two main principles regarding gender: (1) establishing gender equality in mobility opportunities by recognising gender differences in home life, the labour market, and overall lifestyle patterns, and (2) the introduction of gender considerations into the evaluation of transportation projects.

\subsection{Age and Mobility}

As the European Commission argues, "Younger generational cohorts (i.e., Generations $\mathrm{Y}, \mathrm{Z}$, and Alpha) are currently opting for reduced motorisation rates and modal shift away from daily use of the automobile and towards multi-modal shared, public and active travel modes". Younger generations pay more attention to social and environmental problems, and they have received more specific training in sustainability and grown up with a wider technological gap $[10,16]$. In addition, the driving behaviour of young people usually differs from that of older people due to their environmental awareness and technical background $[9,62,63]$. For example, they use more hired or shared cars [64,65]. Moreover, young people usually choose cheaper mobility services, and the price of EVs may be prohibitive for them [16].

Su and Bell [66] suggested that older women's travel patterns have changed in the new millennium, with reduced differences appearing between older men and women. For example, according to the 2009 National Household Travel Survey [67], the gap regarding car driving between older men and women is narrowing. Concerning older people and transportation policy and planning, there are concerns that traditional representations of travel used by planners fail to provide a sufficient basis for consideration [68]. Finally, [13] demonstrated how the analysis of age combined with nationality provided differential and valuable insights while studying other variables like gender or education.

Also, recent studies suggest that ambient air pollutants are risk factors for respiratory infection by carrying microorganisms to make pathogens more invasive to humans and affect bodily immunity by rendering people more susceptible to pathogens (see [69] for a review). The fact that these factors lead to an increased risk of mortality has enhanced the awareness, especially of adults, of the need to reduce ecological damage through different methods, such as EV adoption. However, a recent study conducted by [70] has found that 55 years is the cut-off age after which consumers become reluctant to consider owning an electric car. The main reason for not buying an EV is the fear of range anxiety (the fear of a car coming to a halt because it has run out of battery power before reaching the desired destination).

\subsection{Education and Mobility}

Existing research suggests that people with higher levels of education are more likely to adopt an EV due to more heightened environmental awareness [11,27,71-73]. However, in two studies at the national level, the education variable was not significant [74,75]. Digital education offers an integrated solution for implementing EVs that can help create an interactive learning environment in which the students actively participate [76]. People who have undertaken higher studies are more sensitive to incorporating new technologies into their lives [27]. Promoting aspects like innovation, education, and training seem to be a relevant tool to enhance smart urban mobility. Lytras and Visvizi [77] suggested that citizens with higher educational levels are more aware of technology and, overall, are more prone to use smart-mobility services, such as EVs and smart-mobility applications.

Moreover, their computer literacy is higher than that of people with lower educational levels; consequently, their ability to use EVs is higher (see [78], for a review). In addition, more educated people usually occupy positions of greater responsibility and exert more significant influence over others to promote more sustainable lifestyles [29]. Their advantage in education usually includes more training in technology, which allows them to promote EVs [79]. 


\subsection{Income and Mobility}

Research has shown that EV price and income are essential adoption factors (see [33], for a review). However, a study conducted by [80] in Norway suggested that income is a less prominent indicator when compared with gender, age, and education. They think this is because of the progressive tax system that makes most EVs cheaper than oil models. Although the prices of EVs have reduced in the last few years, some studies show that the production of EVs will remain more expensive for European automakers than standard cars for at least a decade [81]. Overall, the price of EVS, their maintenance, and electricity costs are higher than regular vehicles, and the price of EVs is a dominant adoption factor [82]. Based on panel data for 20 countries, [35] show that the tax reduction policy has significantly positive effects on the penetration of EVs. Moreover, the early adoption of innovations associates with consumer income. Thus, we hypothesise that prospective buyer income is an essential factor in EV adoption.

\section{Sample, Variables, and Methodology}

\subsection{Sample}

To explore the research questions posed above, we propose a quantitative analysis focused on original data on EVs. Similarly to the recent literature on EVs that has examined the rise of "smart mobility" and "smart cities" [6,17,83-85], we conducted a questionnaire.

To create the questionnaire, we analysed previous literature on EV $[10,11,82,84,86]$. We carried out a pre-test questionnaire in two discussion groups composed of two citizen profiles selected with age and attitudinal criteria. The first profile oriented to the quality of life in cities and younger people. The second profile oriented to older people with family and work responsibilities.

After validating the questionnaire (Appendix A), data was collected via the computerassisted web interviewing (CAWI) method from June to July 2019. The CAWI method involves creating a research questionnaire, an internet-based survey technique. The respondent self-administers a survey by following a set of steps and answering questions provided on a website. Unlike telephone studies, surveys via the internet eliminate the influence of the interviewer.

The CAWI questionnaire was our first choice. Several factors drove the selection of this research method. Among them, the desire to reduce the costs and time related to data collection or eliminate errors associated with the inferences of the individual carrying out the survey. Also, to enhance respondents' feeling of anonymity, and obtain respondents using the mailing list while ensuring the random selection of those interviewed regarding the time and place of the survey. The participants evaluated several statements utilising a 5-point Likert scale rated from 1, "not important", to 5, "very important".

We collected a sample of 1205 interviews and distributed it entirely among a sufficiently representative group of medium and large cities. Additionally, we stratified the sample by sex, age, education, and income level. This large-scale sample covered 14 towns and encompassed people from 18 to 60 years old. Appendix B provides demographic information about the individual participants in this study (Table A1).

Focusing on EVs, we aimed to ensure a coherent data set by collecting data from citizens in Spain. Spain was the country selected for analysis because it is at the international forefront of smart cities. Currently, it is difficult to identify a Spanish town that does not have "smart" initiatives in progress. Santander, Barcelona, Malaga, Valencia, and Madrid are pioneering cities with successful, globally recognised experiences in urban transformation [87]. Barcelona was awarded the title "Global Smart City 2015" by an international research study that considered the best uses of connected devices and systems for citizens and visitors [88]. 


\subsection{Measurement of Variables}

\subsubsection{Dependent Variable}

EV was the dependent variable considered in the study. It encompasses all the underlying components that sustain EV infrastructure services. Specifically, we asked citizens about their intention to purchase EVs, the importance of these vehicles in their lives and their propensity to buy EVs based on the available services. These services include charging stations, charging points, and other elements that allow EVs to be driven easily within a city (see Appendix A for a description). The respondents evaluated their intention to purchase through a 5-point Likert scale rated from 1, "low intention" to 5, "high intention".

Table 1 presents the total number of citizens and the average and standard deviation for the three different age groups and gender, education, and income, considered for our dependent variable.

Table 1. Demographics and Descriptive Analysis by Electric Vehicle Infrastructure.

\begin{tabular}{|c|c|c|c|c|c|c|c|c|c|c|}
\hline \multirow[b]{2}{*}{ Age } & & \multicolumn{3}{|c|}{ Men } & \multicolumn{3}{|c|}{ Women } & \multicolumn{3}{|c|}{ Total } \\
\hline & & $N$ & Mean & Std & $N$ & Mean & Std & $N$ & Mean & Std \\
\hline \multirow{3}{*}{ EV } & $18-29$ y.o & 208 & 3.92 & 1.021 & 193 & 3.96 & 1.020 & 401 & 3.94 & 1.019 \\
\hline & $30-45$ y.o & 207 & 4.07 & 0.973 & 195 & 3.83 & 1.014 & 402 & 3.95 & 0.999 \\
\hline & $46-60$ y.o & 189 & 4.06 & 1.003 & 213 & 3.95 & 1.015 & 402 & 4.00 & 1.010 \\
\hline \multicolumn{11}{|c|}{ Education } \\
\hline \multirow{6}{*}{ EV } & "1" No studies certificated & 7 & 3.43 & 0.780 & 2 & 3 & 1.410 & 9 & 3.33 & 0.866 \\
\hline & "2" Basic studies & 14 & 3.79 & 1.360 & 16 & 4 & 0.816 & 30 & 3.9 & 1.094 \\
\hline & "3" Middle diploma & 57 & 4.21 & 0.970 & 45 & 4.2 & 0.967 & 102 & 4.21 & 0.968 \\
\hline & "4" Secondary school & 263 & 4.10 & 0.960 & 246 & 3.88 & 0.996 & 509 & 3.99 & 0.980 \\
\hline & "5" Advanced studies or a degree & 114 & 3.96 & 0.950 & 114 & 3.88 & 1.011 & 228 & 3.93 & 0.979 \\
\hline & "6" Bachelor degree, master or PhD & 149 & 3.87 & 1.060 & 178 & 3.89 & 1.069 & 327 & 3.89 & 1.060 \\
\hline \multicolumn{11}{|c|}{ Income } \\
\hline \multirow{5}{*}{ EV } & " 1 " High purchasing power & 77 & 3.76 & 1.11 & 71 & 3.90 & 1.07 & 148 & 3.83 & 1.09 \\
\hline & "2" High-Medium purchasing power & 190 & 4.06 & 0.95 & 223 & 3.98 & 0.99 & 413 & 4.01 & 0.98 \\
\hline & "3" Medium purchasing power & 251 & 4.07 & 0.95 & 238 & 3.84 & 1.03 & 489 & 3.96 & 0.99 \\
\hline & "4" Medium-low purchasing power & 78 & 4 & 1.14 & 62 & 3.97 & 0.94 & 140 & 3.99 & 1.05 \\
\hline & "5" Low purchasing power & 8 & 3.75 & 0.88 & 7 & 3.71 & 1.25 & 15 & 3.73 & 1.03 \\
\hline Total: & & 604 & 4.01 & 1.000 & 601 & 3.91 & 1.016 & 1205 & 3.96 & 1.009 \\
\hline
\end{tabular}

\subsubsection{Independent Variables}

Considering the research questions regarding the citizen users' socio-demographic characteristics for EV, we selected four independent variables (see Appendix A for a description). Gender: This is a dummy variable that takes a value of " 1 " when the citizens present are men and " 0 " otherwise (i.e., for women). Age: This is a categorical variable that takes a value of " 1 " when the citizen's age is between 18 and 29, " 2 " when it is between 30 and 45, and " 3 " when it is higher than 45 and less than 60. Education: This is a categorical variable that collects information about the educational level of the citizens, based on six categories. The value of " 1 " is for citizens who have no accredited studies but can read and write, "2" for citizens with a certificate of basic studies by a public or private institution and people with a "primary school certificate", "3" for citizens who completed middle school, " 4 " for citizens who completed secondary school or have certificated of vocational training, " 5 " for those who have a certificate of advanced studies or a diploma from a university, and " 6 " for citizens who possess a bachelor's degree, master's, or PhD. Income: This is a categorical variable that collects the purchase level of citizens. We consider five categories of income level: " 1 " if the citizen has a high purchase power, " 2 " if their purchasing power is high-medium, " 3 " if their purchase power is on the average, " 4 " if the citizen has medium-low income and " 5 " when the citizen has a low purchase power. Table 2 shows the descriptive statistics of the variables included in the analysis. 
Table 2. Summary statistics.

\begin{tabular}{llccc}
\hline Variable & Mean/Frequencies (\%) & Standard Deviation & Min. & Max. \\
\hline Ev & 0.96 & 1.009 & 1 & 5 \\
\hline \multirow{2}{*}{ Gender } & $0-0.51$ & 0 & 1 \\
& $1-0.49$ & & 3 \\
Age & $1-0.33$ & 1 & \\
& $2-0.34$ & & \\
& $3-0.33$ & & \\
Education & $1-0.01$ & & \\
& $2-0.03$ & & \\
& $3-0.08$ & & \\
& $4-0.42$ & & \\
Income & $5-0.19$ & & \\
& $6-0.27$ & & \\
& $1-0.12$ & & \\
\end{tabular}

\subsection{Methodology}

We use different methodologies to explore our research questions. Firstly, we use a means comparison method ( $t$-test for equality of means; T Student and Chi-square). We used this methodology to analyse the citizen users' demographic characteristics. We employed a 2 (gender) $\times 3$ (age range) mixed factorial MANOVA design with betweensubject factors of participant gender and age. We analysed the data with SPSS and Stata15 statistical software.

Secondly, we used a clustering methodology to detect any pooling by citizen users' demographic characteristics. We follow the three-step procedure outlined by [88], which has been widely adopted in previous research [89-91]. Thus, we determined the appropriate number of clusters using the hierarchical clustering algorithm developed by [92] complemented by the cubic clustering criterion proposed by [93]. This analysis developed a hierarchical clustering because it does not require a specific and predetermined number of clusters. Specifically, it generates a hierarchy of clusters with $N$ clusters included in the whole sample. Finally, to identify EV preferences, we had developed our clustering procedures outlined by [88]. This clustering provides an established technique for identifying groups with similar demographic characteristics along with the specified cluster variables. This analysis delivered strong support for a four-cluster solution. Then, we assigned the cases in our sample to the appropriate cluster using the k-means clustering method.

Third, we assessed the stability of this cluster assignment using the [94] cross-validation procedure. We performed this analysis to identify individuals with similar patterns. To this end, we created four dummy variables that take one of two possible values: " 1 " = "Belonging to Group 1"; " 0 " = "Belonging to another group". Table 3 shows the cluster citizens considered in each group. The dendrogram generated from the cluster analysis (Appendix C, Figure A1) - a tree-shaped graph representing the agglomeration process taking place in a hierarchical cluster analysis—suggests the existence of four differentiated groups. 
Table 3. Citizens by cluster.

\begin{tabular}{lll}
\hline Cluster & Citizens & \% of the Total \\
\hline Cluster 1 & 159 & $13.20 \%$ \\
Cluster 2 & 386 & $32.03 \%$ \\
Cluster 3 & 288 & $23.90 \%$ \\
Cluster 4 & 372 & $30.87 \%$ \\
Total Sample & 1205 & $100 \%$ \\
\hline
\end{tabular}

Robustness analysis further supports a high level of stability of the results (Using the cross-validation procedure, we randomly split the 1205 usable cases into four halves and applied the k-means clustering method to each half (cf. [94]. We assigned each case to the cluster with the nearest cluster centroid (based on the lowest squared Euclidean distance). Comparing the four cluster assignments for each observation-applying the kmeans clustering method and manually assigning observations based on the nearest cluster centroid - we found that almost $90 \%$ coincided). To identify a coherent group of citizens, we had to validate whether the identified cluster allowed for meaningful interpretations [95]. Table 4 shows the cluster means based on the people's purchase intention for EVs that had also been used to identify the clusters. To determine significant differences for these variables, we compared the means and frequencies of the clusters. On the one hand, in the case of the continuum variables, we compared means employing a t-test since the normality of the variable in each cluster was met. On the other hand, Chi-Squared was used to compare categorical variables of each cluster.

Table 4. Means and variables for cluster.

\begin{tabular}{llc}
\hline Cluster Analysis & & Electric Vehicle Infrastructure \\
\hline \multirow{3}{*}{ Cluster 1 } & $\mathrm{N}$ & 159 \\
& Mean & 2.67 \\
& Standard Deviation & 0.590 \\
\hline \multirow{3}{*}{ Cluster 2 } & $\mathrm{N}$ & 386 \\
& Mean & 3.52 \\
& Standard Deviation & 0.965 \\
\hline \multirow{3}{*}{ Cluster 3 } & $\mathrm{N}$ & 288 \\
& Mean & 4.47 \\
& Standard Deviation & 0.612 \\
\hline \multirow{3}{*}{ Cluster 4 } & $\mathrm{N}$ & 372 \\
& Mean & 4.59 \\
& Standard Deviation & 0.623 \\
\hline \multirow{3}{*}{ Total } & N & 1205 \\
& Mean & 3.96 \\
& Standard Deviation & 1.009 \\
\hline
\end{tabular}

\section{Results}

We examined whether men and women in the three age groups were significantly different from each other within the data analysis. We considered four multivariate tests of significance (Table 5). All of them showed identical results.

A two-way MANOVA revealed a significant multivariate main effect for gender and age, respectively (Wilks' $\lambda=0.975, \mathrm{~F}=6.032$, Wilks' $\lambda=0.959, \mathrm{~F}=5.098, p<0.001$ ). Figure 1 describes the estimated marginal means for the dependent variable graphically. So far, we have analysed gender and age differences regarding EVs among the total sample. An additional question is whether the differences are marked equally among different subgroups. 
Table 5. MANOVA results.

\begin{tabular}{lcccc}
\hline Spain & & \\
\hline Ind. Variable & Value & F & $p$ & $\begin{array}{c}\text { Observed } \\
\text { Power }\end{array}$ \\
\hline Gender & & & & \\
Pillai & 0.025 & 6.032 & 0.000 & 0.996 \\
Wilks & 0.975 & 6.032 & 0.000 & 0.996 \\
Hoteling & 0.025 & 6.032 & 0.000 & 0.996 \\
Roy & 0.025 & 6.032 & 0.000 & 0.996 \\
\hline Age & & & & \\
Pillai & 0.041 & 5.065 & 0.000 & 1.000 \\
Wilks & 0.959 & 5.098 & 0.000 & 1.000 \\
Hoteling & 0.043 & 5.132 & 0.000 & 1.000 \\
Roy & 0.039 & 9.445 & 0.000 & \\
\hline
\end{tabular}

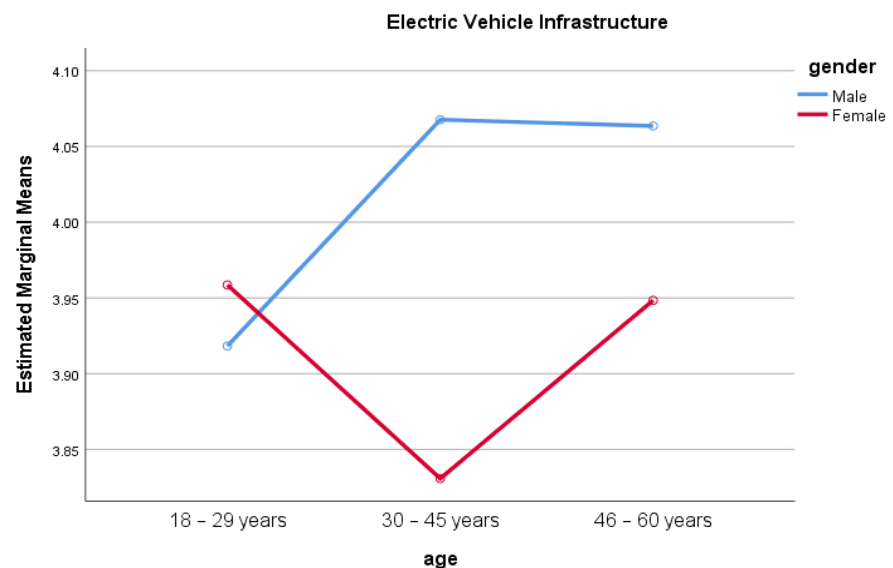

Figure 1. Graph of estimated marginal means for the gender and age groups.

Next, based on the cluster analysis, our results found four groups of statistically different citizens from one another (see Table 6 and Figure 2). Firstly, we compared Cluster 1 and Cluster 2 . As shown in Table 6, there are statistically significant differences by gender $\left(21.58^{* * *}\right)$, educational level $\left(442.05^{* * *}\right)$, and income $\left(105.19^{* * *}\right)$ but not by age (3.09).

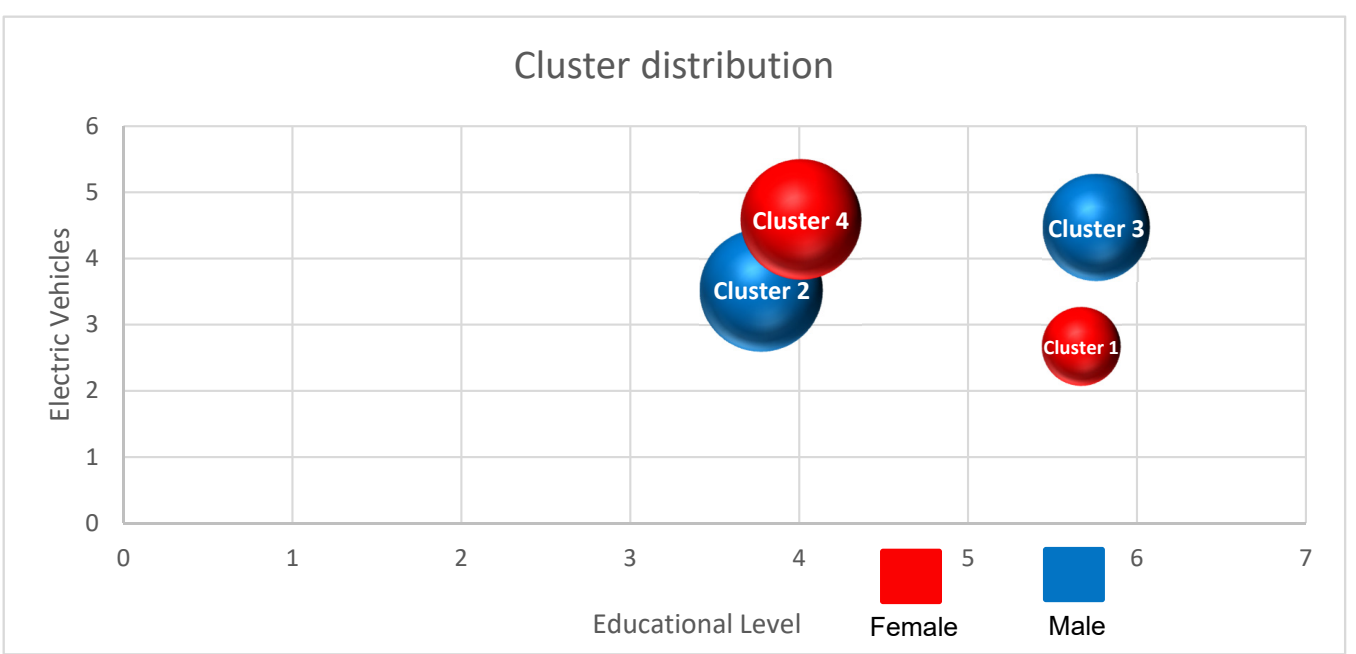

Figure 2. Cluster distribution by education and gender. 
Table 6. Means, frequencies, and cluster differences.

\begin{tabular}{|c|c|c|c|c|c|c|}
\hline & & Gender & Age & $\begin{array}{c}\text { Educational } \\
\text { Level }\end{array}$ & Income & $\begin{array}{l}\text { Electric } \\
\text { Vehicles }\end{array}$ \\
\hline \multicolumn{7}{|c|}{ Cluster Analysis } \\
\hline \multirow[t]{2}{*}{ Cluster 1} & $\mathrm{~N}$ & 159 & 159 & 159 & 159 & 159 \\
\hline & Mean/Frequencies & $\begin{array}{l}0-104 \\
1-55\end{array}$ & $\begin{array}{l}1-54 \\
2-52 \\
3-53\end{array}$ & $\begin{array}{c}1-0 \\
2-0 \\
3-0 \\
4-0 \\
5-52 \\
6-107\end{array}$ & $\begin{array}{c}1-33 \\
2-83 \\
3-37 \\
4-6 \\
5-0\end{array}$ & 2.67 \\
\hline \multirow[t]{2}{*}{ Cluster 2} & $\mathrm{~N}$ & 386 & 386 & 386 & 386 & 386 \\
\hline & Mean/Frequencies & $\begin{array}{l}0-168 \\
1-218\end{array}$ & $\begin{array}{l}1-148 \\
2-138 \\
3-100\end{array}$ & $\begin{array}{c}1-9 \\
2-20 \\
3-52 \\
4-269 \\
5-36 \\
6-0\end{array}$ & $\begin{array}{c}1-26 \\
2-75 \\
3-210 \\
4-63 \\
5-12\end{array}$ & 3.52 \\
\hline \multirow[t]{2}{*}{ Cluster 3} & $\mathrm{~N}$ & 288 & 288 & 288 & 288 & 288 \\
\hline & Mean/Frequencies & $\begin{array}{l}0-167 \\
1-121\end{array}$ & $\begin{array}{c}1-120 \\
2-106 \\
3-62\end{array}$ & $\begin{array}{c}1-0 \\
2-0 \\
3-0 \\
4-0 \\
5-68 \\
6-220\end{array}$ & $\begin{array}{c}1-67 \\
2-152 \\
3-63 \\
4-6 \\
5-0\end{array}$ & 4.47 \\
\hline \multirow[t]{2}{*}{ Cluster 4} & $\mathrm{~N}$ & 372 & 372 & 372 & 372 & 372 \\
\hline & Mean/Frequencies & $\begin{array}{l}0-208 \\
1-164\end{array}$ & $\begin{array}{c}1-79 \\
2-106 \\
3-187\end{array}$ & $\begin{array}{c}1-0 \\
2-10 \\
3-50 \\
4-240 \\
5-72 \\
6-0\end{array}$ & $\begin{array}{c}1-22 \\
2-103 \\
3-179 \\
4-65 \\
5-3\end{array}$ & 4.59 \\
\hline \multicolumn{7}{|c|}{ Cluster Comparisons } \\
\hline Cluster 1-2 & & $21.58^{* * *}$ & 3.09 & $442.05^{* * *}$ & $105.19 * * *$ & $-10.28^{* * *}$ \\
\hline Cluster 1-3 & & $22.43^{* * *}$ & $7.59^{* *}$ & $4.31 * *$ & 1.47 & $-30.00^{* * *}$ \\
\hline Cluster 1-4 & & $4.14^{*}$ & $14.93^{* * *}$ & $387.06^{* * *}$ & $76.62 * * *$ & $-33.02 * * *$ \\
\hline Cluster 2-3 & & 0.153 & 1.82 & $577.81^{* * *}$ & $171.82 * * *$ & $-14.61^{* * *}$ \\
\hline Cluster 2-4 & & $11.63^{* * *}$ & $51.30^{* * *}$ & $25.78^{* * *}$ & $12.38^{* *}$ & $-18.12^{* * *}$ \\
\hline Cluster 3-4 & & $12.54^{* * *}$ & $61.50 * * *$ & $517.81^{* * *}$ & $131.24^{* * *}$ & $-2.60 * * *$ \\
\hline
\end{tabular}

${ }^{*} p<0.1 ;{ }^{* *} p<0.05 ; * * * 0.01$. Chi-Square was provided for categorical variables cluster comparisons while $t$-Student was used for Electric Vehicle variable.

Also, our analysis shows apparent differences among some groups in their preferences regarding the use of EVs. On one side, we have young women with higher educational levels and high-medium purchase power. On the other side, we have young men with lower educational levels and medium purchasing power. The group of young men is concerned with EVs use, but the group of young women pays significantly less attention to them $\left(-10.28^{* * *}\right)$.

Similarly, we compared Clusters 1 and 3 and found statistically significant differences by gender $\left(22.43^{* * *}\right)$ and age $\left(7.59^{* *}\right)$. However, there are no comparatively greater significant differences by educational level $\left(4.31^{* * *}\right)$, and there is no statistically significant difference in terms of income (1.47). Similarly, although both groups have higher education levels, their levels of concern about EV use are entirely different. While young men are concerned with the use of these services, young women pay significantly less attention to them $\left(-30.00^{* * *}\right)$ regardless of their level of income. 
We also compared Clusters 1 and 4 , and we found statistically significant differences by age $\left(14.93^{* * *}\right)$, educational level $\left(387.06^{* * *}\right)$, and income $\left(76.62^{* * *}\right)$. However, there are no comparatively greater significant differences by gender $\left(4.14^{* *}\right)$. In this case, we compared two groups of citizens that are primarily women. Nevertheless, these groups have different concerns about smart mobility. Specifically, older women with less educational and medium purchase power pay significantly more attention to EVs than younger women with high-medium purchase power $\left(-33.02^{* * *}\right)$.

Comparing Clusters 2 and 3 allowed us to find statistically significant differences by educational level (577.81 $\left.{ }^{* *}\right)$ and income $\left(171.82^{* * *}\right)$. The lack of significant differences by gender (0.15) and age (1.82) shows that we compare two groups of men of a similar age. Men with higher educational levels and higher income exhibit a stronger preference for EVs $\left(-14.61^{* * *}\right)$. We also compared Clusters 2 and 4 , finding statistically significant differences by gender $\left(11.63^{* * *}\right)$, age $\left(51.30^{* * *}\right)$, and educational level $\left(25.78^{* * *}\right)$. Additionally, there are also significant differences regarding the use of EVs $\left(-14.61^{* * *}\right)$. However, there are less differences in terms of income $\left(12.38^{* *}\right)$. This result means that older women with less education have a higher level of awareness regarding EVs than do younger men with higher educational levels regardless of their income level.

Finally, based on the comparison of Clusters 3 and 4 , we detected statistically significant differences by gender $\left(12.54^{* * *}\right)$, age $\left(61.50^{* * *}\right)$, educational level $\left(517.81^{* * *}\right)$ and income $\left(131.24^{* * *}\right)$. Furthermore, the presence of significant negative differences for the use of EVs $\left(-2.60^{* * *}\right)$ shows that older women were highly motivated to use EVs although they have significantly less income.

\section{Discussion}

This study aimed to determine the demographic profile of prospective Spanish buyers of EVs. After identifying four different EV users' clusters, we now take an in-depth look at and discuss the characteristic cluster differences to clarify their demand response.

One of the most surprising results of this research is the gender differences because, in general, men were more aware than women regarding the use of EVs. This result differs from most previous studies [11], which showed women as more likely than men to adopt sustainable travel behaviours because of their social values, empathy, and engagement with environmental problems $[10,25]$. A recent study that explores if the gender gap tends to disappear in sustainability [23] supports the fact that men have a stronger preference for EVs than women. Another explanation for this finding could be that women usually prefer public transportation, while others argue that driving in cities is less attractive to them [96]. ClosinGap [97], a platform created through the cooperation of some of the most important firms in Spain, such as MAPFRE, Vodafone, Repsol, Meliá, BMW, among others, argues that most women use public transportation, while men are opting for a personal vehicle. The gender difference is six points higher for women in bus and train use, four points higher in the metro, and one point higher in trams. In addition, masculinity is traditionally associated with technological innovation and femininity with sustainability [98]. This association could be a cause of women's weaker preference for EVs.

Our findings also suggest that gender alone is not enough to justify a stronger preference for EVs. The educational level plays an essential role in the choice of citizens for EVs [11,82]. After exploring educational characteristics, we found that men exhibit a stronger preference for EVs at higher levels of education than do women. The level of education can be a possible explanation of the stronger EV preference of men. This higher level of interest may be due to education contributing to increasing their level of empathy and environmental awareness and to their desire to experiment with new and different products and services. This conclusion finds support in previous literature [99] that suggested that education contributes to breaking up the traditional sustainability roles associated with women.

The age of users also plays a significant role in EV preferences [11,16]. Although, traditionally, new technologies are associated with young people [16], our study suggests that 
older and middle-aged people exhibit stronger EV preferences. Indeed, in the 18-29 age group, men and women showed weaker preferences for EVs. This result is similar to other studies in countries like South Korea [100] and contrary to Nordic Countries [73]. One reason could be the decline in car licenses among young adults [101]. In general, this group feels more comfortable using smart-mobility service-oriented technology and is less product-oriented, primarily due to scant economic resources. Indeed, young people understand smart mobility as focusing mainly on bike-sharing, car-sharing, and ridesharing [85]. Our study finds support in previous electromobility studies that showed that middle-aged respondents had a more optimistic attitude to EVs than did members of younger generations [102]. Maybe a public policy that disseminates more knowledge about EVs needs to be implemented among younger users, especially knowledge about the differences, disadvantages, and advantages of EVs [84].

However, it was from the middle-aged group that we gleaned our most exciting insights [63]. Middle-aged men exhibited a stronger preference for EVs than middle-aged women with similar educational levels and the same age or less. This middle-aged group includes three of the four clusters considered. As the ClosinGap report shows, women make more carpooling, while men opt for personal transportation. The report notes that women continue to opt more for carpooling ( $11 \%$ compared to $9 \%$, respectively), in which several passengers travel together and share expenses. This service is much more prevalent among them.

On the contrary, men continue to opt for individual options that may include carsharing ( $8 \%$ versus $5 \%$, respectively). These differences are also reflected in short trips (precisely those trips for which EVs are most helpful) since women rely more on urban buses ( $21 \%$ versus $18 \%$, respectively). Another essential aspect that could explain the difference between men and women in this age group is the lack of information for drivers about recharging and batteries. Moreover, it is necessary to consider the influence of power plants [103]. This lack of information impacts the absence of knowledge about the maintenance cost of an EV versus a combustion-engine vehicle or aspects related to the car's configuration. This difference could be due to the tendency of men to take risks more than women in an uncertain or more unfamiliar situation. It might also be explained by men tending to adopt a technology in the process of being implemented, such as the electric car, instead of women who, in general, are more conservative and cautious. The sales of EVs reflect this fact: $69 \%$ of the vehicles sold by Tesla in the first quarter of 2019 in the United States were purchased by men, compared to just $31 \%$ by women. Other electric models, such as the Chevrolet Bolt and Nissan LEAF, have a distribution like that of Tesla (the Chevy has $69 \%$ men buyers versus 31\% women, while the Nissan has $66 \%$ men versus $34 \%$ women).

Finally, if we focus on age, older men displayed a stronger preference for EVs than women. However, when we consider other variables, such as educational level, women in the old-age group have the strongest EV preference. As mentioned above, the explanation might be that women are more involved in sustainable mobility and tend to use public transportation or car-sharing services. Nevertheless, older women are less likely to use these types of services and prefer individual mobility. Another potential explanation is that older people are more sensitive to respiratory diseases, which leads to them increasing their efforts to reduce ecological damage through certain environmental practices like driving EVs. Their more outstanding commitment to EVs might also be due to the more significant amount of experience they have gained and their more substantial economic resources, which allow them to purchase these more expensive types of vehicles.

\section{Managerial and Policy Implications}

Our findings have important implications for managers, marketers, buyers, and policymakers. We believe that our research is especially timely in the aftermath of the COVID-19 pandemic and answers the United Nations Environment Assembly (UNEA) call 
for citizens and decision-makers to become more sensitive to sustainability and achieve its Sustainable Development Goals.

Accordingly, the results of this study unveiled some remarkable differences from previous literature, for example, the unexpected preferences of women towards EV, highlighting the importance of EV-user profiling in creating an adequate strategy for automotive manufacturers and policymakers. The early stages of the adoption curve in EV markets need a deep understanding of consumers' evolution and the respective demand response of automotive firms. This study corroborates the stronger user preference for EVs due to the increase in sustainable behaviour in society. It is relevant to consider internal consumer motivations for preferring EVs, such as sustainable consumption attitudes and normative and hedonic motivations [82,104,105].

Second, among the four clusters identified in this study, there are relevant differences that the automotive industry should consider. One such difference is that women buy $55 \%$ of crossovers, and they have a primary influence in the purchase of some $85 \%$ of all new vehicles; however, women purchased just $30 \%$ of EVs. These firms should know that this percentage is remarkably similar all over the world. Our results show that middle-aged men with high levels of education represent a good market niche for these vehicles as they are currently conceived. However, automotive firms should implement different strategies to incentivise younger people and women to use EVs. Women require simplicity, comfort, and cheaper and quieter EVs with more neutral designs. Moreover, these users desire a safe vehicle that reduces their fear of running out of electricity on the road.

Gender-sensitive measures should be put in place to tailor EVs to meet the different needs of the genders. Key lessons may yield insights that help ensure that both men and women benefit equitably from the promise of EVs. A further element lies in the possibility of women participating effectively in the planning process to design measures to address their mobility needs better.

Furthermore, the automotive industry should pay particular attention to higher educated and younger women because this market niche presents a weaker preference for these vehicles. The firms involved should strengthen the sustainable benefits of EVs that women require and introduce effective marketing and communication strategies that ease their fear of using these vehicles. Changing EV design, increasing advertising showing women in EVs, and modifying sustainable business strategies are critical aspects to capturing this market niche. Also, managers should design business strategies that focus increased attention on younger people due to their weaker preference for EVs. Younger generations have fewer incentives to obtain driver's licenses and use a higher proportion of shared transportation. Automotive firms should design cheaper EVs and, due to the more considerable awareness of sustainability of younger people, target their marketing strategies to anticipate their emotions by offering these people an opportunity to protect the environment. Targeting these consumer groups is a challenge because this segment holds the inherent belief that EVs are too expensive, unsafe and that their design is too masculine. Also, these groups represent important market niches for the automotive industry now and in the foreseeable future.

\section{Limitations and Future Research}

Some limitations should be noted in the present study. First, although we collected the data from various Spanish cities, it reduces the generalizability of this study's findings to other countries. However, due to the proliferation of similar studies, future research will undoubtedly be able to look at whether the results of this study hold in different countries or conduct country comparisons.

Second, our study focuses on user intentions to adopt an EV and only one question was formulated to analyse their propensity to buy. Further research may seek to compare intention with purchase behaviour and include more items to quantify better their propensity to buy. As [106] showed, "measuring intention provides important insights into 
the behaviour and its motivation" [106] (p. 1280), although just half of the people who intended to perform a particular behaviour followed through.

Third, more socio-demographic characteristics should be investigated, providing more details about the EV user profile. Coffman et al. [82] suggested that more attention needs to be focused on the perspectives of education, income, number/type of cars owned, level of environmentalism, and love of technology. Similarly, [83] suggested focusing on the quality of life, including culture, health, housing, and education as relevant factors that could influence EV adoption preferences. Moreover, the fact that younger men and women pay less attention to EVs is relevant. These results demand further research to determine whether the characteristics of this generation could be determinants of the future of smart mobility.

Future research should investigate whether the above prospective buyers' groups are similar in other countries, especially in those polluted environments and with higher risks of respiratory diseases, such as COVID-19, that call for environmental governance. Future research should look into the level of women's representation on such teams. In 2020, most EU countries had no significant cities with a woman as mayor, and only seven of the $28 \mathrm{EU}$ capitals had a woman leader (Rome, Paris, Bucharest, Sofia, Stockholm, Amsterdam, and Luxembourg). In Europe, women represent, on average, only $26.65 \%$ of elected municipal councillors [107]. Similarly, future research should investigate the composition of teams of smart-mobility stakeholders. A gender-sensitive stakeholder analysis can be undertaken throughout all stages of the smart-mobility project cycle (the design, implementation, and usage phases). Also, future research should investigate the development of gender indicators to measure progress toward targets that themselves need to be gender-sensitive.

This study mainly focused on EV adoption at the national level. We suggest that future research should also include an analysis of EV adoption in some leading cities because some cities are at the forefront of the smart cities' revolution and smart mobility. This is also consistent with the investment in EV charging stations, which appears to be done at the regional or city level, as most driving occurs within urban areas [108].

Governments and firms in the automotive industry are developing several sustainable strategies to incentivise EV adoption, for example, tax reduction incentives. Further research should explore the effectiveness of these sustainable strategies in different demographic groups.

\section{Conclusions}

Although EVs provide many benefits in sustainability and the environment, getting users to adopt EVs is not easy. This study contributes some novel insights to the scarce research on this topic by showing the importance of socio-demographic characteristics in profiling prospective buyers of EVs. Overall, the findings suggest that there is a potential need to design EV adoption strategies that are tailored to specific socio-demographic clusters.

Despite the scarcity of socio-demographic EV adoption studies per country, other research studies using some of the socio-demographic variables examined in this study show similar results in other countries, particularly in the most advanced countries in terms of EV adoption such as Sweden or South Korea. Our study, on the other hand, emphasizes the importance of combining more socio-demographic variables in order to gain a better understanding of EV adoption. The EV adoption has not achieved the expected results in many countries, but many countries are accelerating their efforts by increase investments and create new mobility policies. While our study is limited to a single country (Spain), we believe it can provide valuable insights into EV deployment in other countries as well

Our research revealed that gender differences exist even among the most educated EV users. We can conclude that, in general, men have a strong preference for EVs. However, it is striking that older women are the most EV-aware group; their remarkable automotive experience and concern for sustainability could be among the causes of their stronger preference for EVs. Another fascinating insight is the stronger preference for EVs of older people. Especially remarkable is the case of young women, who are not interested in this 
type of service. Another critical insight emerging from this study is that income level appears to be a better predictive EV adoption factor for men than for women.

Finally, the results of this research may contribute to the development of policies and strategies oriented toward achieving a higher-level preference for EVs in certain socio-demographic groups.

Author Contributions: Conceptualisation, J.E. and G.d.H.; Data curation, D.A.-M.; Formal analysis, D.A.-M.; Methodology, D.A.-M.; Project administration, J.E.; Supervision, J.E. and G.d.H.; Validation, D.A.-M.; Writing—original draft, D.A.-M., J.E. and G.d.H.; Writing—review \& editing, J.E. All authors have read and agreed to the published version of the manuscript.

Funding: This work was supported by the Spanish Ministry of Science and Innovation under grant PID2019-105140RB-I00.

Institutional Review Board Statement: Not applicable.

Informed Consent Statement: Not applicable.

Data Availability Statement: Data available on request due to restrictions eg privacy or ethical.

Conflicts of Interest: The authors declare no conflict of interest. The founding sponsors had no role in the study's design; in the collection, analyses, or interpretations of data; in the writing of the manuscript, and in the decision to publish the results.

\section{Appendix A}

CLASSIFICATION DATA

\section{GENDER}

- Male

- Female

\section{AGE}

- Less than 18 years

Not included

- 18 to 29 years

1

- 30 to 45 years

2

- 46 to 60 years

3

- More than 60 years

Not included

\section{CITY}

○ Málaga 1

- Santander 2

- Barcelona 3

- Madrid 4

- Bilbao 5

- Coruña 6

- Valencia $\quad 7$

- Sevilla 8

- Vigo 9

- Las Palmas de Gran Canaria 10

- Lleida 11

- Guadalajara 12

- Girona 13

○ Logroño 14

- OTHERS

○ Others 15 


\section{EDUCATION}

Higher Level of Studies Completed

- No studies accredited but can read and write $\quad 1$

- Certificate of basic studies 2

- Middle diploma 3

- Secondary school 4

- Advanced studies or degree 5

- Bachelor's degree, Master's, or PhD 6

\section{INCOME}

- "1" High purchasing power 1

- "2" High-Medium purchasing power 2

- " 3 " Medium purchasing power 3

- " 4 " Medium-low purchasing power 4

- "5" Low purchasing power 5

\section{ELECTRIC MOBILITY}

Please evaluate in through a 5-point Likert scale rated from 1, "low intention" to 5, "high intention" your intention to purchase EVs, the importance of these vehicles in your live and your propensity to buy EVs based on the available services:

ELECTRIC VEHICLE understood as (number of charging point networks, information systems on location and availability, public electric vehicle rental systems...).

\section{Appendix B}

Table A1. Demographics and Descriptive Analysis.

\begin{tabular}{|c|c|c|c|c|c|c|c|c|c|c|}
\hline & \multicolumn{3}{|c|}{ Men } & \multicolumn{3}{|c|}{ Women } & \multicolumn{3}{|c|}{ Total } & \multirow[t]{2}{*}{ Total } \\
\hline & $18-29 y$ & $30-45 y$ & $46-60 y$ & $18-29 y$ & $30-45 y$ & $46-60 y$ & $18-29 y$ & $30-45 y$ & $46-60 y$ & \\
\hline Barcelona & 26 & 9 & 16 & 18 & 14 & 27 & 44 & 23 & 43 & 110 \\
\hline Bilbao & 7 & 13 & 12 & 4 & 16 & 11 & 11 & 29 & 23 & 63 \\
\hline A Coruña & 1 & 9 & 7 & 8 & 21 & 13 & 9 & 30 & 20 & 59 \\
\hline Girona & 6 & 11 & 13 & 11 & 9 & 17 & 17 & 20 & 30 & 67 \\
\hline Guadalajara & 3 & 11 & 7 & 12 & 5 & 13 & 15 & 16 & 20 & 51 \\
\hline $\begin{array}{c}\text { Las Pal- } \\
\text { mas/Canaria }\end{array}$ & 15 & 36 & 22 & 18 & 22 & 20 & 33 & 58 & 42 & 133 \\
\hline Lleida & 9 & 10 & 12 & 6 & 12 & 16 & 15 & 22 & 28 & 65 \\
\hline Logroño & 8 & 11 & 7 & 10 & 18 & 8 & 18 & 29 & 15 & 62 \\
\hline Madrid & 45 & 31 & 24 & 21 & 22 & 30 & 66 & 53 & 54 & 173 \\
\hline Malaga & 11 & 19 & 9 & 14 & 9 & 9 & 25 & 28 & 18 & 71 \\
\hline Santander & 10 & 8 & 10 & 8 & 16 & 5 & 18 & 24 & 15 & 57 \\
\hline Sevilla & 37 & 18 & 24 & 37 & 11 & 19 & 74 & 29 & 43 & 146 \\
\hline Valencia & 14 & 6 & 15 & 14 & 7 & 14 & 28 & 13 & 29 & 70 \\
\hline Vigo & 16 & 15 & 11 & 12 & 13 & 11 & 28 & 28 & 22 & 78 \\
\hline
\end{tabular}




\section{Appendix C}

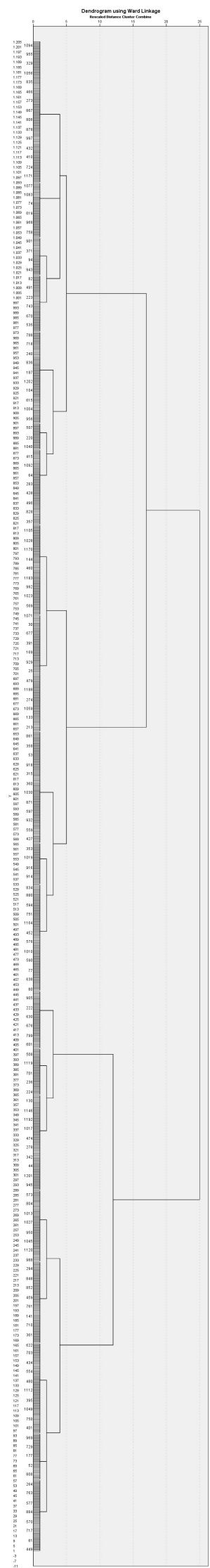

Figure A1. The dendrogram generated from the cluster analysis. 


\section{References}

1. González-Sánchez, G.; Olmo-Sánchez, M.I.; Maeso-González, E. Challenges and Strategies for Post-COVID-19 Gender Equity and Sustainable Mobility. Sustainability 2021, 13, 2510. [CrossRef]

2. Kraemer, M.U.G.; Yang, C.-H.; Gutierrez, B.; Wu, C.-H.; Klein, B.; Pigott, D.M.; du Plessis, L.; Faria, N.R.; Li, R.; Hanage, W.P. The effect of human mobility and control measures on the COVID-19 epidemic in China. Science 2020, 6490, 493-497. [CrossRef]

3. Xie, J.; Zhu, Y. Association between ambient temperature and COVID-19 infection in 122 cities from China. Sci. Total Environ. 2020, 724, 138201. [CrossRef]

4. Arribas-Ibar, M.; Nylund, P.A.; Brem, A. The Risk of Dissolution of Sustainable Innovation Ecosystems in Times of Crisis: The Electric Vehicle during the COVID-19 Pandemic. Sustainability 2021, 13, 1319. [CrossRef]

5. United Nations Department of Economic and Social Affairs. World Population Prospects: The 2018 Revision; UNDESA: New York, NY, USA, 2018.

6. Feng, S.; An, H.; Li, H.; Qi, Y.; Wang, Z.; Guan, Q.; Li, Y.; Qi, Y. The technology convergence of electric vehicles: Exploring promising and potential technology convergence relationships and topics. J. Clean. Prod. 2020, 260, 120992. [CrossRef]

7. Shaheen, S.; Chan, N. Mobility and the Sharing Economy: Potential to Facilitate the First- and Last-Mile Public Transit Connections. Built Environ. 2016, 42, 573-588. [CrossRef]

8. Allied Market Research Electric Vehicle Market by Type. Available online: https://www.alliedmarketresearch.com/electricvehicle-market (accessed on 30 April 2021).

9. Caulfield, B.; Farrell, S.; McMahon, B. Examining individuals preferences for hybrid electric and alternatively fuelled vehicles. Transp. Policy 2010, 17, 381-387. [CrossRef]

10. Ghasri, M.; Ardeshiri, A.; Rashidi, T. Perception towards electric vehicles and the impact on consumers' preference. Transp. Res. Part D Transp. Environ. 2019, 77, 271-291. [CrossRef]

11. Liao, F.; Molin, E.; van Wee, B. Consumer preferences for electric vehicles: A literature review. Transp. Rev. 2017, 37, 252-275. [CrossRef]

12. Diamantopoulos, A.; Schlegelmilch, B.B.; Sinkovics, R.R.; Bohlen, G.M. Can socio-demographics still play a role in profiling green consumers? A review of the evidence and an empirical investigation. J. Bus. Res. 2003, 56, 465-480. [CrossRef]

13. Oliveira, G.D.; Dias, L.C. Influence of Demographics on Consumer Preferences for Alternative Fuel Vehicles: A Review of Choice Modelling Studies and a Study in Portugal. Energies 2019, 12, 318. [CrossRef]

14. Moore, G.A.; McKenna, R. Crossing the Chasm; Capstone Oxford: London, UK, 1999.

15. Stafford, E.R. Bridging the Chasm: An Early Adopter's Perspectives on How Electric Vehicles Can Go Mainstream. Sustain. J. Rec. 2017, 10, 164-176. [CrossRef]

16. Hidrue, M.K.; Parsons, G.R.; Kempton, W.; Gardner, M.P. Willingness to pay for electric vehicles and their attributes. Resour. Energy Econ. 2011, 33, 686-705. [CrossRef]

17. Wu, J.; Liao, H.; Wang, J.-W. Analysis of consumer attitudes towards autonomous, connected, and electric vehicles: A survey in China. Res. Transp. Econ. 2020, 80, 100828. [CrossRef]

18. Price, D.A.; Wang, Z. Explaining an Industry Cluster: The Case of US Car Makers From 1895-1969. Econ. Brief 2012, EB12-10, 1-5.

19. Trappey, C.; Trappey, A.; Liu, C.-S.; Lee, W.; Hung, Y. The Design and Evaluation of a Supply Chain Logistic Hub for Automobile and Parts Distribution. Mater. Sci. Forum. Mater. Sci. Forum. 2008, 594, 119-131. [CrossRef]

20. Morton, C.; Anable, J.; Nelson, J.D. Consumer structure in the emerging market for electric vehicles: Identifying market segments using cluster analysis. Int. J. Sustain. Transp. 2017, 11, 443-459. [CrossRef]

21. Crozier, C.; Apostolopoulou, D.; McCulloch, M. Mitigating the impact of personal vehicle electrification: A power generation perspective. Energy Policy 2018, 118, 474-481. [CrossRef]

22. Kubiczek, J.; Hadasik, B. Segmentation of Passenger Electric Cars Market in Poland. World Electr. Veh. J. 2021, 12, 23. [CrossRef]

23. Christidis, P.; Focas, C. Factors affecting the uptake of hybrid and electric vehicles in the European Union. Energies 2019, $12,3414$. [CrossRef]

24. Hanson, S. Gender and mobility: New approaches for informing sustainability. Gender Place Cult. 2010, 17, 5-23. [CrossRef]

25. Jensen, A.F.; Cherchi, E.; Mabit, S.L. On the stability of preferences and attitudes before and after experiencing an electric vehicle. Transp. Res. Part D Transp. Environ. 2013, 25, 24-32. [CrossRef]

26. Kim, J.; Rasouli, S.; Timmermans, H. Expanding scope of hybrid choice models allowing for mixture of social influences and latent attitudes: Application to intended purchase of electric cars. Transp. Res. Part A Policy Pract. 2014, 69, 71-85. [CrossRef]

27. Vassileva, I.; Campillo, J. Adoption barriers for electric vehicles: Experiences from early adopters in Sweden. Energy 2017, 120, 632-641. [CrossRef]

28. Cresswell, T.; Priya Uteng, T. Gendered Mobilities: Towards an Holistic Understanding. In Gendered Mobilities; Ashgate: Aldershot, UK, 2008; pp. 47-64.

29. Mouter, N.; van Cranenburgh, S.; van Wee, B. An empirical assessment of Dutch citizens' preferences for spatial equality in the context of a national transport investment plan. J. Transp. Geogr. 2017, 60, 217-230. [CrossRef]

30. Simmons, G.; Giraldo, J.E.D.; Truong, Y.; Palmer, M. Uncovering the link between governance as an innovation process and socio-economic regime transition in cities. Res. Policy 2018, 47, 241-251. [CrossRef]

31. Straughan, R.D.; Roberts, J.A. Environmental segmentation alternatives: A look at green consumer behavior in the new millennium. J. Consum. Mark. 1999, 16, 558-575. [CrossRef] 
32. Canepa, K.; Hardman, S.; Tal, G. An early look at plug-in electric vehicle adoption in disadvantaged communities in California. Transp. Policy 2019, 78, 19-30. [CrossRef]

33. Higueras-Castillo, E.; Molinillo, S.; Coca-Stefaniak, J.A.; Liébana-Cabanillas, F. Potential Early Adopters of Hybrid and Electric Vehicles in Spain-Towards a Customer Profile. Sustainability 2020, 12, 4345. [CrossRef]

34. Trommer, S.; Jarass, J.; Kolarova, V. Early adopters of electric vehicles in Germany unveiled. World Electr. Veh. J. 2015, 7, 722-732. [CrossRef]

35. Xue, C.; Zhou, H.; Wu, Q.; Wu, X.; Xu, X. Impact of Incentive Policies and Other Socio-economic Factors on Electric Vehicle Market Share: A Panel Data Analysis from the 20 Countries. Sustainability 2021, 13, 2928. [CrossRef]

36. Costa Pinto, D.; Herter, M.M.; Rossi, P.; Borges, A. Going green for self or for others? Gender and identity salience effects on sustainable consumption. Int. J. Consum. Stud. 2014, 38, 540-549. [CrossRef]

37. Daziano, R.A.; Bolduc, D. Incorporating pro-environmental preferences towards green automobile technologies through a Bayesian hybrid choice model. Transp. A Transp. Sci. 2013, 9, 74-106. [CrossRef]

38. Hackbarth, A.; Madlener, R. Consumer preferences for alternative fuel vehicles: A discrete choice analysis. Transp. Res. Part D Transp. Environ. 2013, 25, 5-17. [CrossRef]

39. Tanaka, M.; Ida, T.; Murakami, K.; Friedman, L. Consumers' willingness to pay for alternative fuel vehicles: A comparative discrete choice analysis between the US and Japan. Transp. Res. Part A Policy Pract. 2014, 70, 194-209. [CrossRef]

40. Shin, J.; Bhat, C.R.; You, D.; Garikapati, V.M.; Pendyala, R.M. Consumer preferences and willingness to pay for advanced vehicle technology options and fuel types. Transp. Res. Part C Emerg. Technol. 2015, 60, 511-524. [CrossRef]

41. Zhang, Y.; Yu, Y.; Zou, B. Analysing public awareness and acceptance of alternative fuel vehicles in China: The case of EV. Energy Policy 2011, 39, 7015-7024. [CrossRef]

42. Hwang, J.; Griffiths, M. Share more, drive less: Millennials value perception and behavioral intent in using collaborative consumption services. J. Consum. Mark. 2017, 34, 132-146. [CrossRef]

43. Dempsey, A. Why Are Millennials Buying Fewer Cars. Ph.D. Thesis, The Ohio State University, Columbus, OH, USA, 2016.

44. Anderson, J.; Rainie, L.; Vogels, E. Experts Say the 'New Normal' in 2025 Will Be Far More Tech-Driven, Presenting More Big Challenges. 2021. Available online: https / / www.pewresearch.org/internet/2021/02/18/experts-say-the-new-normal-in-20 25-will-be-far-more-tech-driven-presenting-more-big-challenges (accessed on 30 April 2021).

45. Fry, R. Young adults after the recession: Fewer homes, fewer cars, less debt. PEW Res. Center 2013, 21, 1-41.

46. Kampman, B.E.; Verbeek, R.; Grinsven, A.H.; van Mensch, P.; Croezen, H.J.; Patuleia, A. Bringing Biofuels on the Market: Options to Increase EU Biofuels Volumes Beyond the Current Blending Limits; CE Delft: Delft, The Netherlands, 2013.

47. WHO. Global Status Report on Road Safety 2018. Available online: https://www.who.int/news-room/fact-sheets/detail/roadtraffic-injuries (accessed on 21 June 2021).

48. Cecere, G.; Corrocher, N.; Gossart, C.; Ozman, M. Technological pervasiveness and variety of innovators in Green ICT: A patent-based analysis. Res. Policy 2014, 43, 1827-1839. [CrossRef]

49. Helmers, E.; Marx, P. Electric cars: Technical characteristics and environmental impacts. Environ. Sci. Eur. 2012, 24, 14. [CrossRef]

50. Larminie, J.; Lowry, J. Electric Vehicle Technology Explained; John Wiley \& Sons: Hoboken, NJ, USA, 2012; ISBN 111994273X.

51. De Hoog, J.; Handberg, K.; Jegatheesan, R. Demonstrating demand management: How intelligent EV charging can benefit everyone. World Electr. Veh. J. 2013, 6, 881-892. [CrossRef]

52. Lieven, T. Policy measures to promote electric mobility-A global perspective. Transp. Res. Part A Policy Pract. 2015, 82, 78-93. [CrossRef]

53. van der Steen, M.; Van Schelven, R.M.; Kotter, R.; Van Twist, M.J.W.; Peter van Deventer, M.P.A. EV policy compared: An international comparison of governments' policy strategy towards e-mobility. In E-Mobility in Europe; Springer: Berlin/Heidelberg, Germany, 2015; pp. 27-53.

54. Chekima, B.; Wafa, S.A.; Igau, O.A.; Chekima, S.; Sondoh, S.L. Examining green consumerism motivational drivers: Does premium price and demographics matter to green purchasing? J. Clean. Prod. 2016, 112, 3436-3450. [CrossRef]

55. Gatignon, H.; Robertson, T.S. A Propositional Inventory for New Diffusion Research. J. Consum. Res. 1985, 11, 849-867. [CrossRef]

56. Hardman, S.; Lee, J.H.; Tal, G. How do drivers use automation? Insights from a survey of partially automated vehicle owners in the United States. Transp. Res. Part A Policy Pract. 2019, 129, 246-256. [CrossRef]

57. Crane, R. Is there a quiet revolution in women's travel? Revisiting the gender gap in commuting. J. Am. Plan. Assoc. 2007, 73, 298-316. [CrossRef]

58. Kawgan-Kagan, I. Early adopters of carsharing with and without BEVs with respect to gender preferences. Eur. Transp. Res. Rev. 2015, 7, 33. [CrossRef]

59. Sánchez, M.I.O.; González, E.M. Gender Differences in Commuting Behavior: Women's Greater Sensitivity. Transp. Res. Procedia 2016, 18, 66-72. [CrossRef]

60. Räty, R.; Carlsson, K.A. Energy consumption by gender in some European countries. Energy Policy 2010, 38, 646-649. [CrossRef]

61. European Union. Treaty of Amsterdam Amending the Treaty on European Union, the Treaties Establishing the European Communities and Certain Related Acts; European Union: Luxembourg, 1997.

62. Davis, J.D.; Papandonatos, G.D.; Miller, L.A.; Hewitt, S.D.; Festa, E.K.; Heindel, W.C.; Ott, B.R. Road Test and Naturalistic Driving Performance in Healthy and Cognitively Impaired Older Adults: Does Environment Matter? J. Am. Geriatr. Soc. 2012, 60, 2056-2062. [CrossRef] [PubMed] 
63. Musti, S.; Kockelman, K.M. Evolution of the household vehicle fleet: Anticipating fleet composition, PHEV adoption and GHG emissions in Austin, Texas. Transp. Res. Part A Policy Pract. 2011, 45, 707-720. [CrossRef]

64. Burrows, A.; Bradburn, J.; Cohen, T. Journeys of the future: Introducing Mobility as a Service. Atkins Mobil. 2015, 1-36. Available online: https:/ / exploreconsulting.careers/uploads/Atkins-Journeys-of-the-future_300315.pdf (accessed on 30 April 2021).

65. Johanson, J.; Vahlne, J.-E. The Uppsala internationalisation process model revisited: From liability of foreignness to liability of outsidership. J. Int. Bus. Stud. 2009, 40,1411-1431. [CrossRef]

66. Su, F.; Bell, M.G.H. Travel differences by gender for older people in London. Res. Transp. Econ. 2012, 34, 35-38. [CrossRef]

67. U.S. Department of Transportation. National Household Travel Survey; Federal Highway Administration and Bureau of Transportation Statistics: Washington, DC, USA, 2009.

68. Banister, D.; Bowling, A. Quality of life for the elderly: The transport dimension. Transp. Policy 2004, 11, 105-115. [CrossRef]

69. Zhu, Y.; Xie, J.; Huang, F.; Cao, L. Association between short-term exposure to air pollution and COVID-19 infection: Evidence from China. Sci. Total Environ. 2020, 727, 138704. [CrossRef]

70. KPMG Over 55s Reluctant to Join Electric Vehicle Revolution, KPMG Survey Finds. Available online: https://home.kpmg/uk/en/ home/media/press-releases / 2019/11/over-55-s-reluctant-to-join-electric-vehicle-revolution-kpmg-survey-finds.html (accessed on 30 April 2021).

71. Almeida Neves, S.; Marques, A.C.; Fuinhas, J.A. Technological progress and other factors behind the adoption of electric vehicles: Empirical evidence for EU countries. Res. Transp. Econ. 2019, 74, 28-39. [CrossRef]

72. Axsen, J.; Goldberg, S.; Bailey, J. How might potential future plug-in electric vehicle buyers differ from current "Pioneer" owners? Transp. Res. Part D Transp. Environ. 2016, 47, 357-370. [CrossRef]

73. Sovacool, B.K.; Kester, J.; Noel, L.; de Rubens, G.Z. The demographics of decarbonising transport: The influence of gender, education, occupation, age, and household size on electric mobility preferences in the Nordic region. Glob. Environ. Chang. 2018, 52, 86-100. [CrossRef]

74. Li, X.; Chen, P.; Wang, X. Impacts of renewables and socio-economic factors on electric vehicle demands-Panel data studies across 14 countries. Energy Policy 2017, 109, 473-478. [CrossRef]

75. Sierzchula, W.; Bakker, S.; Maat, K.; van Wee, B. The influence of financial incentives and other socio-economic factors on electric vehicle adoption. Energy Policy 2014, 68, 183-194. [CrossRef]

76. Conrads, J.; Rasmussen, M.; Winters, N.; Geniet, A.; Langer, L. Digital Education Policies in Europe and Beyond: Key Design Principles for More Effective Policies; Joint Research Centre (Seville Site): Luxembourg, 2017.

77. Lytras, M.D.; Visvizi, A. Who uses smart city services and what to make of it: Toward interdisciplinary smart cities research. Sustainability 2018, 10, 1998. [CrossRef]

78. Jin, L.; Slowik, P. Literature Review of Electric Vehicle Consumer Awareness and Outreach Activities; International Council on Clean Transportation: San Francisco, CA, USA, 2017. Available online: https//www.theicct.org/sites/default/files/publications/ Consumer-EV-Awareness_ICCT_Working-Paper_23032017_vF.pdf (accessed on 22 March 2021).

79. Docherty, I.; Marsden, G.; Anable, J. The governance of smart mobility. Transp. Res. Part A Policy Pract. 2018, 115, 114-125. [CrossRef]

80. Bjerkan, K.Y.; Nørbech, T.E.; Nordtømme, M.E. Incentives for promoting Battery Electric Vehicle (BEV) adoption in Norway. Transp. Res. Part D Transp. Environ. 2016, 43, 169-180. [CrossRef]

81. Financial Times Electric Car Costs to Remain Higher Than Traditional Engines. Available online: https://www.ft.com/content/ a7e58ce7-4fab-424a-b1fa-f833ce948cb7 (accessed on 23 May 2021).

82. Coffman, M.; Bernstein, P.; Wee, S. Electric vehicles revisited: A review of factors that affect adoption. Transp. Rev. 2017, 37, 79-93. [CrossRef]

83. Cledou, G.; Estevez, E.; Soares Barbosa, L. A taxonomy for planning and designing smart mobility services. Gov. Inf. Q. 2018, 35, 61-76. [CrossRef]

84. Fang, Y.; Wei, W.; Mei, S.; Chen, L.; Zhang, X.; Huang, S. Promoting electric vehicle charging infrastructure considering policy incentives and user preferences: An evolutionary game model in a small-world network. J. Clean. Prod. 2020, $258,120753$. [CrossRef]

85. Moscholidou, I.; Pangbourne, K. A preliminary assessment of regulatory efforts to steer smart mobility in London and Seattle. Transp. Policy 2019, 98, 170-177. [CrossRef]

86. Ge, Y.; Knittel, C.R.; MacKenzie, D.; Zoepf, S. Racial and Gender Discrimination in Transportation Network Companies. Natl. Bur. Econ. Res. 2016, 22776. [CrossRef]

87. Seisdedos, G. Smart Cities: La Transformación Digital de las Ciudades; Instituto de Empresa-PwC, Ed.; Centro de Innovación del Sector Público de PWC e IE Business School: Madrid, Spain, 2015.

88. Sorrell, S. Reducing energy demand: A review of issues, challenges and approaches. Renew. Sustain. Energy Rev. 2015, 47, 74-82. [CrossRef]

89. Arundel, A.; Casali, L.; Hollanders, H. How European public sector agencies innovate: The use of bottom-up, policy-dependent and knowledge-scanning innovation methods. Res. Policy 2015, 44, 1271-1282. [CrossRef]

90. de Jong, J.P.J.; von Hippel, E.; Gault, F.; Kuusisto, J.; Raasch, C. Market failure in the diffusion of consumer-developed innovations: Patterns in Finland. Res. Policy 2015, 44, 1856-1865. [CrossRef] 
91. Guan, J.C.; Yan, Y. Technological proximity and recombinative innovation in the alternative energy field. Res. Policy 2016, 45, 1460-1473. [CrossRef]

92. Ward, J.H. Hierarchical Grouping to Optimise an Objective Function. J. Am. Stat. Assoc. 1963, 58, 236-244. [CrossRef]

93. Sarle, W.S. Cubic Clustering Criterion; SAS Institute Inc.: Cary, NC, USA, 1983.

94. Homburg, C.; Jensen, O.; Krohmer, H. Configurations of Marketing and Sales: A Taxonomy. J. Mark. 2008, 72, 133-154. [CrossRef]

95. McIntyre, R.M.; Blashfield, R.K. A nearest-centroid technique for evaluating the minimum-variance clustering procedure. Multivar. Behav. Res. 1980, 15, 225-238. [CrossRef]

96. Rich, P. The Organizational Taxonomy: Definition and Design. Acad. Manag. Rev. 1992, 17, 758-781. [CrossRef]

97. ClosinGap ClosinGap. Available online: https:/ / closingap.com/ (accessed on 22 April 2021).

98. Anfinsen, M.; Lagesen, V.A.; Ryghaug, M. Green and gendered? Cultural perspectives on the road towards electric vehicles in Norway. Transp. Res. Part D Transp. Environ. 2019, 71, 37-46. [CrossRef]

99. Organisation for Economic Co-operation and Development. Gender and Sustainable Development: Maximising the Economic, Social and Environmental Role of Women; OECD Publishing: Paris, France, 2008; ISBN 9264049908.

100. Lashari, Z.A.; Ko, J.; Jang, J. Consumers' Intention to Purchase Electric Vehicles: Influences of User Attitude and Perception. Sustainability 2021, 13, 6778. [CrossRef]

101. DGT. Driver's License in Spain. Available online: http:/ /www.dgt.es/es/seguridad-vial/estadisticas-e-indicadores/permisosconduccion/series-historicas/ (accessed on 15 May 2021).

102. She, Z.-Y.; Sun, Q.; Ma, J.-J.; Xie, B.-C. What are the barriers to widespread adoption of battery electric vehicles? A survey of public perception in Tianjin, China. Transp. Policy 2017, 56, 29-40. [CrossRef]

103. Kahlen, M.T.; Ketter, W.; van Dalen, J. Electric Vehicle Virtual Power Plant Dilemma: Grid Balancing Versus Customer Mobility. Prod. Oper. Manag. 2018, 27, 2054-2070. [CrossRef]

104. Axsen, J.; TyreeHageman, J.; Lentz, A. Lifestyle practices and pro-environmental technology. Ecol. Econ. 2012, 82, 64-74. [CrossRef]

105. Bailey, J.; Miele, A.; Axsen, J. Is awareness of public charging associated with consumer interest in plug-in electric vehicles? Transp. Res. Part D Transp. Environ. 2015, 36, 1-9. [CrossRef]

106. Rezvani, Z.; Jansson, J.; Bengtsson, M. Consumer motivations for sustainable consumption: The interaction of gain, normative and hedonic motivations on electric vehicle adoption. Bus. Strateg. Environ. 2018, 27, 1272-1283. [CrossRef]

107. Sundström, A. Women's local political representation within 30 European countries. QoG Work. Pap. Ser. 2013, $2013,18$.

108. Hall, D.; Lutsey, N. Charging Infrastructure in Cities: Metrics for Evaluating Future Needs. Working Paper 2020-17, 2020, International Council on Clean Transportation. Available online: https://theicct.org/sites/default/files/publications/EVcharging-metrics-aug2020.pdf (accessed on 15 April 2021). 